\title{
Author Correction: Beta Trace Protein does not outperform Creatinine and Cystatin $C$ in estimating Glomerular Filtration Rate in Older Adults
}

\begin{abstract}
Natalie Ebert ${ }^{1}$, Camilla Koep ${ }^{1}$, Kristin Schwarz ${ }^{1}$, Peter Martus ${ }^{2}$, Nina Mielke ${ }^{1}$, Jan Bartel ${ }^{3}$, Martin Kuhlmann ${ }^{4}$, Jens Gaedeke ${ }^{5}$, Markus Toelle ${ }^{6}$, Markus van der Giet ${ }^{6}$, Mirjam Schuchardt ${ }^{6}$ \& Elke Schaeffner ${ }^{1}$

Correction to: Scientific Reports https://doi.org/10.1038/s41598-017-12645-4, published online 04 October 2017.

This Article contains errors in the results of the Full Age Spectrum (FAS) $)_{(\mathrm{crea} / \mathrm{cys})}$. For the original calculation of mean bias, SD of differences, P10 and P30 value as well as Bland Altman in Figure 3 the rescaling factor for Serum creatinine (Scr) was switched for females and males.
\end{abstract}

As a result, in the Results section, under subheading 'Performance of BTP based estimating equations and comparison with established equations',

"All in all the BIS2 showed the best performance, which is not surprising since it was developed from the BIS dataset, and the FAS was relatively equal to $\operatorname{Inker}_{(\mathrm{BTP})}$ and superior to CKD-EPI $\left.\mathrm{Crea/CysC}\right)$ "

should read:

"All in all the BIS2 showed the best performance, which is not surprising since it was developed from the BIS

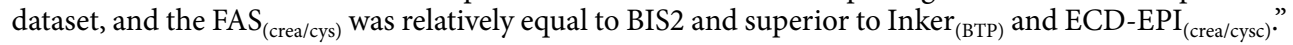

In addition, the correct Table 3, showing the correct details for the $\mathrm{FAS}_{(\mathrm{Crea} / \mathrm{Cys})}$ row, is shown below as Table 1. 


\begin{tabular}{|c|c|c|c|c|}
\hline Equation & $\begin{array}{l}\text { Mean Bias } \\
\left(\mathrm{ml} / \mathrm{min} / 1.73 \mathrm{~m}^{2}\right)\end{array}$ & $\begin{array}{l}\text { SD of Differences } \\
\left(\mathrm{ml} / \mathrm{min} / 1.73 \mathrm{~m}^{2}\right)\end{array}$ & $\begin{array}{l}\text { P10 } \\
(\%)\end{array}$ & $\begin{array}{l}\text { P30 } \\
(\%)\end{array}$ \\
\hline Pöge $_{(\mathrm{BTP})}$ & 3.50 & 11.5 & 45.2 & 85.2 \\
\hline Pöge $_{\text {(BTP/Crea) }}$ & 2.38 & 10.4 & 44.9 & 87.8 \\
\hline White $_{(\text {BTP/Crea) }}$ & 25.88 & 13.0 & 3.4 & 25.6 \\
\hline Inker $_{(\mathrm{BTP})}$ & -2.00 & 10.9 & 44.9 & 90.5 \\
\hline BIS2* & -0.15 & 7.7 & 60.1 & 96.6 \\
\hline CKD-Epi $_{(\mathrm{Crea} / \mathrm{Cys})}$ & 6.95 & 8.9 & 39.6 & 88.2 \\
\hline FAS $_{(\text {Crea/Cys })}$ & -0.32 & 8.0 & 57.1 & 96.3 \\
\hline
\end{tabular}

Table 1. Bias, Precision, and Accuracy for eGFR Equations containing BTP in Individuals aged 70 years and above. Detailed description of GFR estimating equations can be found in the material section. BIS = Berlin Initiative Study, CKD-EPI = Chronic Kidney Disease, FAS = Full age spectrum. Bias was defined as difference between eGFR and mGFR for each equation. P10 and P30 refer to percentage differences [(eGFR - mGFR)/ mGFR $\times 100]$. *The results of the BIS2 differ slightly from former publications ${ }^{3}$ where the validation of the equation within the BIS data set was performed in only half of the iohexol population. For comparison reasons the current validation for BIS2 was done in the entire BIS iohexol population $(n=566)$ including the development sample leading to a slightly more favorable result.

Finally, the correct Figure 3, containing the correct Bland-Altman plot for $\mathrm{FAS}_{(\mathrm{Crea} / \mathrm{Cys})}$ in panel b, appears below as Figure 1.

a)
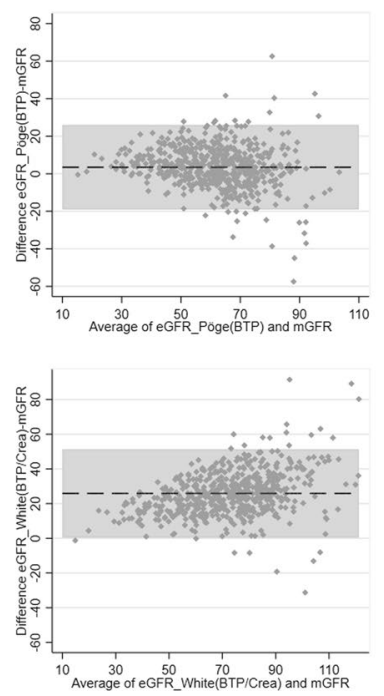
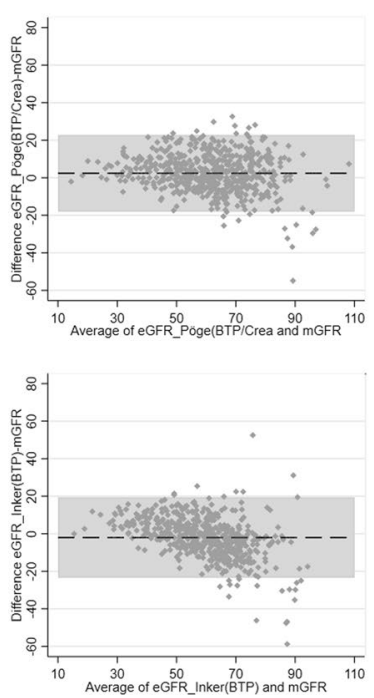

b)
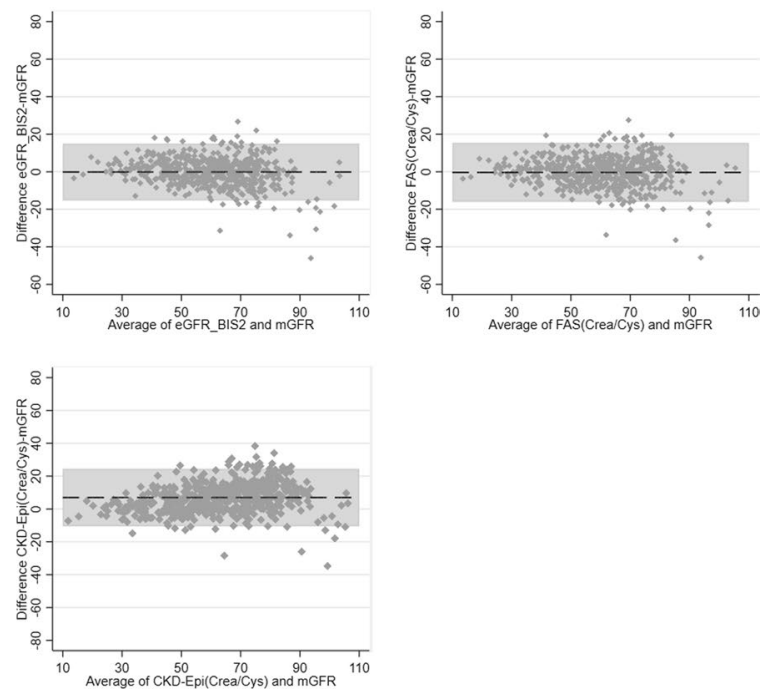

Figure 1. (a) Bland and Altman of BTP-based eGFR-equations versus mGFR. (b) Bland and Altman of creatinine-/cystatin C-based eGFR-equations versus mGFR. (a) and (b) Bland and Altman plots of BTP-based and combined creatinine/cystatin C-based eGFR-equations versus mGFR $(n=566)$. The bias is represented by the dashed middle line. The horizontal grey bar represents the area between the upper and lower limits of the interval of agreement. $\mathrm{mGFR}=$ measured glomerular filtration rate; eGFR = estimated glomerular filtration rate; $\mathrm{BIS}=$ Berlin Initiative Study; CKD-Epi = Chronic Kidney Disease Epidemiology Collaboration, FAS = Full Age Spectrum. For details about the GFR estimating equations please refer to the material section.

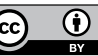

Open Access This article is licensed under a Creative Commons Attribution 4.0 International License, which permits use, sharing, adaptation, distribution and reproduction in any medium or format, as long as you give appropriate credit to the original author(s) and the source, provide a link to the Creative Commons license, and indicate if changes were made. The images or other third party material in this article are included in the article's Creative Commons license, unless indicated otherwise in a credit line to the material. If material is not included in the article's Creative Commons license and your intended use is not permitted by statutory regulation or exceeds the permitted use, you will need to obtain permission directly from the copyright holder. To view a copy of this license, visit http://creativecommons.org/licenses/by/4.0/.

(C) The Author(s) 2019 